\title{
Disposição a pagar pelo uso de unidades de conservação urbanas: parque da cidade Mãe Bonifácia, Cuiabá-MT
}

Disposition to pay for the use of urban conservation unit: Mãe Bonifácia city park, Cuiabá-MT

\author{
Disposition à payer par l'usage d'unités d'entretien urbaines: parc ville Mãe \\ Bonifácia, Cuiabá-MT
}

Disposición a pagar por el uso de las unidades de conservacion urbanas: parque de la cidad Mãe Bonifacia, Cuiabá-MT

\author{
Sílvia Regina Fernandes Volanova* \\ José Franklim Chichorro** \\ Carlos Alberto Simões de Arruda***
}

Recebido 6/8/2009; revisado e aprovado em 17/12/2009; aceito em 25/1/2010

\begin{abstract}
Resumo: O presente estudo teve por objetivo identificar a disposição dos usuários do "Parque da Cidade Mãe Bonifácia", Cuiabá-MT, a pagar por seu uso, caracterizando também o perfil dos usuários. Os resultados mostram que $27,5 \%$ dos entrevistados estão dispostos a pagar um valor de entrada para a manutenção do Parque. O perfil do usuário foi composto por classe média a alta (renda familiar média superior a 10 salários mínimos), elevado grau de instrução (49,5\% com nível superior completo). A criação de novos parques e áreas verdes foi apontada como um investimento importante por $89,5 \%$ dos entrevistados.
\end{abstract}

Palavras-chave : Valoração contingente. Parque urbano. Cuiabá.

Abstract: This paper objective is to identify the "Parque da Cidade Mãe Bonifácia", Cuiabá-MT user's disposition to pay, and also to characterize there profile as well. The research was carried through in December/2006. The results show that $27,5 \%$ of the interviewed ones agreed to pay a value of entrance for the maintenance of the park. The profile of the users was composed of middle to high-class (familiar income average higher than $\mathrm{R} \$ 3,500,00$ ), high degree of education $(49,5 \%$ with graduation ). The creation of new parks and green areas was indicated as an important investment by $89,5 \%$ of the interviewed.

Key-words: Contingent valuation. Urban park. Cuiabá.

Résumé: L'étude ci-jointe a eu pour but identifier la disposition à payer des usagers du "Parque da Cidade Mãe Bonifácia", Cuiabá-MT, caractérisant ainsi le profil des usagers. Les résultats montrent que $27,5 \%$ des interviewés acceptent de payer une taxe d'entrée pour l'entretien du Parc. Le profil de l'usager a été constitué par l'échelle moyenne à haute (budget familial moyen ou supérieur à 10 salaires minimums), degré élévé d'instruction (49,5\% avec niveau supérieur complet). La création de nouveaux parcs et de zones vertes a été indiquée comme un investissement important par $89,5 \%$ des interviewés.

Mots-clés: Mise en valeur contingent. Parc urbain. Cuiabá.

Resumen: Este estudio tuvo como objetivo identificar la dispositión a pagar de los usuarios del "Parque da Cidade Mãe Bonifácia", Cuiabá-MT, tambiem con el perfil de los usuarios. Los resultados muestran que el 27,5\% de los encuestados entán despuestos a pagar uma cantidad de La entrada para el mantenimento del parque. El perfil del usuario se compone de la clase media a alta (ingresos familiares por encima de 10 salarios mínimos), el alto nivel de educacíon (49,5\% com nível superior completo). La creación de nuevos parques y zonas verdes se intificó como uma inversión importante por el 89,5\% de los encuestados.

Palabras clave: Valoración contingente. Parque urbano. Cuiabá.

\section{Introdução}

O acelerado crescimento urbano e a consequente alteração da paisagem e das características ambientais, principalmente nas grandes cidades, têm gerado uma série de problemas ambientais afetando a qualidade de vida de suas populações (CAVALHEIRO \& DEL PICCHIA, 1992).

Dessa forma, a conservação de áreas naturais no ambiente urbano é justificada pelo seu potencial em realçar aspectos

\footnotetext{
* Mestre em Ciências Florestais pela Universidade Federal de Mato Grosso (UFMT). E-mail: vilanova.silvia@gmail.com

** Coordenador do Mestrado em Engenharia Florestal da Universidade Federal do Espírito Santo (UFES). E-mail: jfranklim@terra.com.br

*** Mestre em Ciências Florestais pela UFMT. E-mail: arrudacarlos33@yahoo.com.br
} 
associados à qualidade ambiental e enquanto provedora de benefícios ao homem, interferindo positivamente na qualidade de vida pela manutenção das funções ambientais, sociais e estéticas, amenizando as propriedades negativas da urbanização (MENEZES, 2005).

Apesar de reconhecida a necessidade de investimento na conservação da natureza nas áreas urbanas e estando prevista na legislação brasileira onde destacam-se o Código Florestal, o Estatuto da Cidade e, no caso de Cuiabá, o Sistema Municipal de Conservação da Natureza, as considerações políticas e econômicas tornam o estabelecimento de áreas protegidas dentro do perímetro urbano difícil: o custo da terra é alto e a maior parte dos espaços é privada.

Conforme destacado por Hildebrand et al. (2002), os parques urbanos fazem parte de um contexto maior dentro da administração e das políticas públicas no qual os orçamentos são sempre limitados diante da infinidade de serviços e necessidades a serem satisfeitas. Desta forma, investimentos em implantação e manutenção de parques, bosques e outras áreas verdes concorrem igualmente com investimentos em educação, saúde, saneamento básico, entre outros.

Sendo assim, a mensuração da disposição dos visitantes a pagar pelo uso dessas áreas pode indicar aos gestores de recursos ambientais com orçamentos limitados quais são as prioridades da sociedade, permitindo um melhor controle e gerenciamento das demandas, fornecendo informações que subsidiem a tomada de decisão do poder público e da sociedade civil sobre o gerenciamento dos recursos naturais e propicia a realização de uma análise social de custo-benefício para reservas naturais (ORTIZ et al., 2001).

O levantamento das características do público que frequenta os parques é também muito importante por permitir compreender melhor quem, quantos, quando e por que as pessoas fazem uso do parque, bem como se consideram necessário o investimento público na criação de mais áreas verdes.

Dentro desse contexto, este estudo teve como objetivo identificar a disposição dos usuários a pagar pelo uso do "Parque da Cidade Mãe Bonifácia", Cuiabá-MT, bem como caracterizar o perfil de seus usuários.

\section{Metodologia}

\section{1 Área de estudo}

O Parque da Cidade Mãe Bonifácia (PCMB) localiza-se na região oeste de Cuiabá, Mato Grosso, entre as coordenadas geográficas $15^{\circ} 34^{\prime} 44^{\prime \prime}$ S e $56^{\circ} 05^{\prime} 016^{\prime \prime} \mathrm{W}$, com 77,16 hectares de área.

A área do parque foi, primeiramente, transformada em Unidade de Conservação de Interesse Local pela Lei Complementar de Gerenciamento Urbano n. 004, de 24 de dezembro de 1992 (CUIABÁ, 1992). Posteriormente, o Governo do Estado transformou-a em Parque Estadual, pelo Decreto $n$. 1.470 , de 9 de junho de 2000 (MATO GROSSO, 2000) sendo gerenciada pela Secretaria do Estado de Meio Ambiente (SEMA).

Neste ativo natural, os usuários encontram um remanescente de cerca de 66 hectares de Cerrado lato sensu que permite a existência de uma variada fauna.

Além das belezas naturais, com seu entorno urbanizado, o Parque conta com três portais de acesso, com a Praça do Cerrado, onde são promovidos eventos culturais; sede administrativa, onde funciona também a biblioteca e uma área para exposições; mirante; $6,961 \mathrm{~km}$ de trilhas pavimentadas e três espaços para a prática de exercícios físicos (Figura 1). 

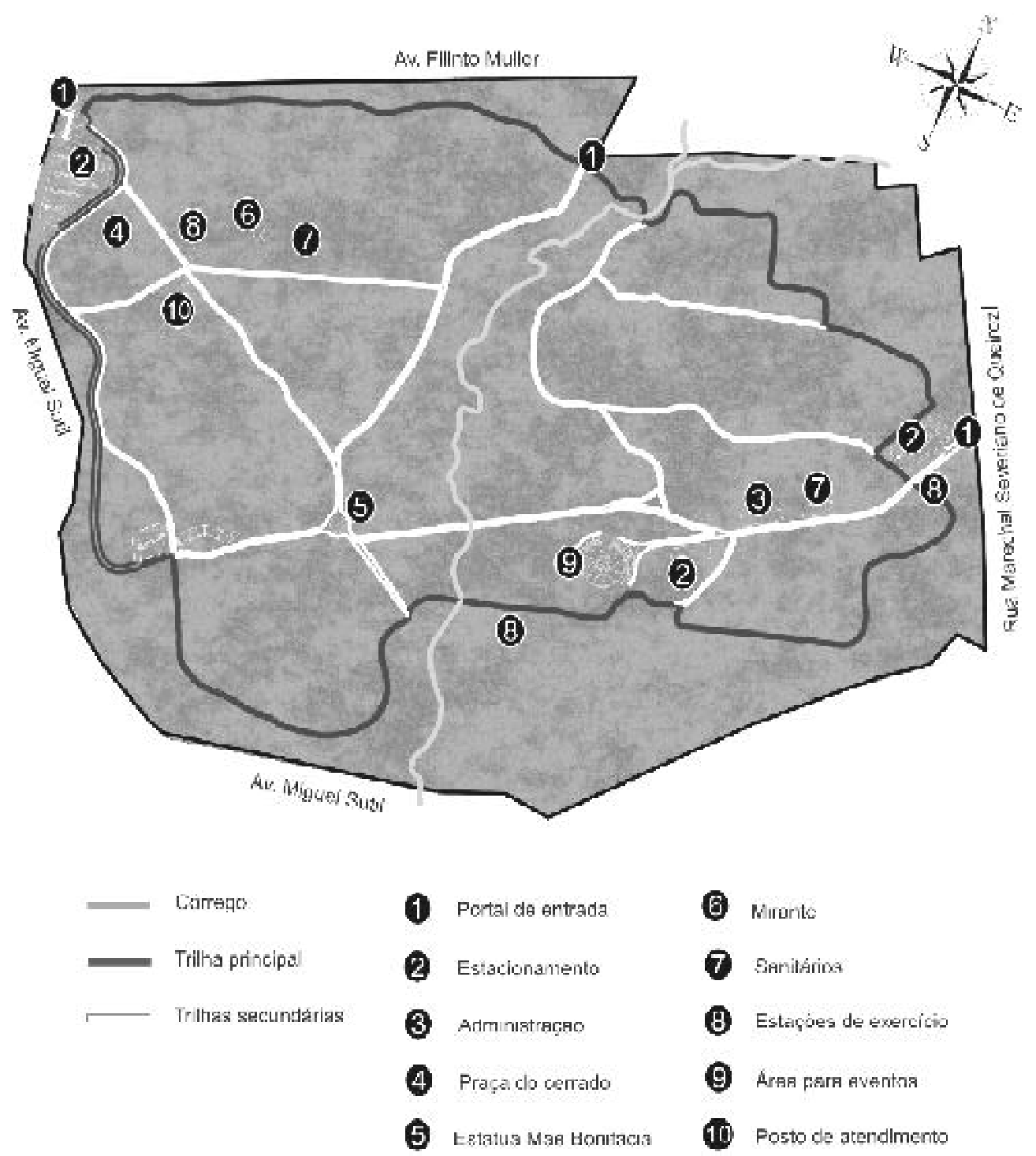

Figura 1 - Croqui do Parque da Cidade Mãe Bonifácia, Cuiabá-MT.

Tudo isso contribui para que o PCMB seja considerado como um dos maiores pontos de atração da cidade para a recreação e o lazer da população metropolitana, recebendo em torno de 240.000 visitantes por ano, o que representa $45,5 \%$ da população cuiabana.

\subsection{Intensidade amostral}

Tendo como parâmetro a média mensal de 20 mil visitantes, registrada sistematicamente pela administração do Parque nos últimos dois anos, optou-se por aplicar a fórmula proposta por Cochran (1977), indicada para situações nas quais a população é grande (acima de 10.000). O questionário é pou- co extenso (com até 30 perguntas fechadas) e as respostas são mutuamente excludentes.

Utilizou-se a seguinte fórmula:

$$
n=\frac{Z^{2} p q}{E^{2}}
$$

Em que:

$\mathrm{n}$ = tamanho da amostra;

pq = variabilidade do fenômeno estudado;

$\mathrm{E}=$ precisão com que os resultados serão generalizados;

$\mathrm{Z}$ = nível de confiança.

Inicialmente foram aplicados 110 questionários, implicando $10 \%$ de erro. Foram então acrescidos 90 questionários, de forma que o erro foi reduzido a $7 \%$. 


\subsection{Disposição a pagar}

Para estimar a disposição a pagar (DAP) média dos entrevistados, foi utilizada a expressão abaixo:

$$
D A P M=\sum_{i=1}^{y} D A P\left(N_{i} / N\right)(X)
$$

Em que:

DAPM = valor médio da disposição a pagar;

$\mathrm{DAP}=$ disposição a pagar;

ni = número de entrevistados dispostos

a pagar;

$\mathrm{N}=$ número total de pessoas entrevistadas;

$\mathrm{y}=$ número de intervalos relativos às respostas quanto à DAP;

$\mathrm{i}=\mathrm{um}$ dos intervalos relativos às respostas quanto à DAP;

$\mathrm{X}=$ número de visitantes habitantes estimado na área, durante o período em estudo.

Após a tabulação dos resultados foi possível obter o valor médio encontrado, extrapolando para o total de visitantes, representando, assim, o valor dos benefícios atribuídos à área.

\subsection{Coleta de Dados}

A pesquisa foi realizada por meio da aplicação do questionário em entrevistas pessoais e individuais, realizadas no período de 4 a 11 de dezembro de 2007, considerando todos os dias da semana (segunda a domingo) nos períodos matutino e vespertino, em três pontos de grande fluxo de pessoas. A amostra foi aleatória, exigindo apenas que o entrevistado tivesse idade mínima de 20 anos e renda mensal.

Depois de definida a primeira versão do questionário, realizou-se uma pesquisa piloto para teste dos questionários, antes da sua aplicação final.

O questionário foi dividido em quatro partes: perfil dos entrevistados, atividades recreacionais, importância atribuída às áreas verdes e disposição a pagar.

Após a descrição do PCMB foi feita uma explicação sobre os custos de manutenção do Parque e, em seguida, foi colocada a seguinte pergunta: "O custo para manutenção de parques (limpeza, plantio, segurança) é altíssimo, inviabilizando a conservação adequada do espaço (principalmente a reposição de patrimônio depredado). Você acha justo o pagamento de entrada para a visitação (destinando o fundo para a manutenção e conservação do Parque)?".

Em caso de resposta afirmativa, era acrescida a pergunta: "A té quanto você estaria disposto a pagar pela entrada para visitar o Parque da Cidade Mãe Bonifácia?". O intervalo das respostas foram agrupados em 3 classes de valores: de $\mathrm{R} \$ 0,50$ à $\mathrm{R} \$ 1,00 ;>\mathrm{R} \$$ 1,00 até $\mathrm{R} \$ 3,00 ; \mathrm{e}>\mathrm{R} \$ 3,00$ até $\mathrm{R} \$ 5,00$.

Em caso de resposta negativa, era acrescida a pergunta: "Qual a justificativa para a disposição a não pagar pela manutenção e conservação do PCMB?".

\section{Resultados e discussão}

\subsection{Número de amostras}

A partir da média de 20 mil visitantes/ mês foram realizadas 200 entrevistas. Considerando as respostas da pergunta sobre disposição a pagar como indicador de variabilidade, pode-se afirmar, com 95\% de confiança, que os valores da pesquisa variaram 0,42 em relação à média verdadeira.

\subsection{Perfil dos usuários}

O Parque da Cidade Mãe Bonifácia é visitado, em sua maioria, por moradores de Cuiabá $(95,5 \%)$, sendo que $64,5 \%$ moram a até $3 \mathrm{~km}$ de distância do Parque, 21,5\% a até $6 \mathrm{~km}$ de distância e 9,5\% a mais de $9 \mathrm{~km}$ de distância.

Esse resultado é semelhante ao encontrado em outros estudos, como no levantamento realizado no Parque Ingá, Maringá-PR, onde $52 \%$ dos usuários eram moradores de bairros circunvizinhos (TAKAHASHI e MARTINS, 1990), no Parque Florestal de Sinop-MT, com 73\% dos frequentadores residentes nas proximidades do Parque (PERON,2003). Nos parques de São Paulo-SP esse percentual é de 54,8\% (SANTOS e COSTA, 2005) e 79\% no Parque Natural Municipal do Mendanha, Rio de Janeiro-RJ (TOMIAZZI et al., 2006).

A faixa etária dos entrevistados do PCMB apresentou os seguintes valores: $27 \%$ 
entre 50 e 59 anos, $26 \%$ entre 40 e 49 anos, $21 \%$ entre 20 e 29 anos, $19 \%$ entre 30 e 39 anos e 7\% com mais de 60 anos. Quanto ao gênero, $51 \%$ dos frequentadores são do sexo feminino e $49 \%$ do sexo masculino.
Com relação à renda familiar foram consideradas sete categorias (Tabela 1 ), sendo que a maioria dos frequentadores, $44,5 \%$, possui renda familiar superior a $\mathrm{R} \$ 3.500,00$ mensais.

Tabela 1 - Renda familiar mensal dos visitantes do Parque da Cidade Mãe Bonifácia Cuiabá-MT.

\begin{tabular}{|c|c|}
\hline Renda Familiar Mensal & $\%$ \\
\hline até 1 salário mínimo $(\mathrm{R} \$ 380,00)$ & $1,5 \%$ \\
\hline de 1 a 3 salários mínimos ( $R \$ 380,00$ a $R \$ R \$ 1.140,00)$ & $6,5 \%$ \\
\hline de 3 a 5 salários mínimos ( $\mathrm{R} \$ 1.140,00$ a $\mathrm{R} \$ 1.900,00)$ & $14,0 \%$ \\
\hline de 5 a 7 salários mínimos ( $R$ \$ 1.900,00 a $R \$ 2660,00)$ & $15,5 \%$ \\
\hline de 7 a 10 salários mínimos ( $\mathrm{R} \$ 2.660,00$ a $\mathrm{R} \$ 3.800,00$ & $18,0 \%$ \\
\hline Acima de 10 salários mínimos (acima de $\mathrm{R} \$ 3.800,00$ ) & $44,5 \%$ \\
\hline
\end{tabular}

De acordo com os resultados, foram consideradas seis categorias de educação formal, sendo que $49,5 \%$ dos usuários possuem ensino superior completo (Tabela 2).

Tabela 2 - Nível de escolaridade dos visitantes do Parque da cidade Mãe Bonifácia, Cuiabá-MT.

\begin{tabular}{lc}
\hline \multicolumn{1}{c}{ Nível de Escolaridade } & $\%$ \\
\hline Ensino fundamental incompleto & $3,5 \%$ \\
Ensino fundamental completo & $4,0 \%$ \\
Ensino médio incompleto & $5,0 \%$ \\
Ensino médio completo & $26,5 \%$ \\
Ensino superior incompleto & $11,5 \%$ \\
Ensino superior completo & $49,5 \%$ \\
\hline
\end{tabular}

Em relação ao grau de escolaridade dos entrevistados, no Parque Natural Municipal do Mendanha (TOMIAZZI et al., 2006), o nível médio foi o mais representativo, com $47 \%$. Já no Bosque do Alemão, Curitiba-PR, $43,2 \%$ dos frequentadores possuem nível superior completo (HILDEBRAND et al., 2002). No Parque Florestal de Sinop-MT, $69 \%$ dos entrevistados possuíam 1o grau completo (PERON, 2003).

\subsection{Atividades recreacionais}

Quanto à frequência (Tabela 3) dos entrevistados, $78 \%$ afirmaram frequentar o PCMB pelo menos uma vez por semana, de acordo com Malta (2008), podendo ser considerados requentadores. Os demais $(21,5 \%)$ são considerados visitantes.

Tabela 3 - Frequência dos usuários do Parque da cidade Mãe Bonifácia Cuiabá-MT

\begin{tabular}{lc}
\hline \multicolumn{1}{c}{ Frequência } & $\%$ \\
\hline Três vezes por semana & $64 \%$ \\
Duas vezes por semana & $9 \%$ \\
Uma vez por semana & $5 \%$ \\
Ocasional & $19 \%$ \\
Primeira visita & $2,5 \%$ \\
\hline
\end{tabular}

Os entrevistados que frequentam o Parque mais de 3 vezes por semana são compostos, em sua maioria (44,5\%), pelos moradores que residem a distâncias de até $3 \mathrm{~km}$ do Parque.

Quanto ao período em que os entrevistados frequentam o Parque, $47 \%$ preferem o matutino, $39 \%$ o vespertino, e $14 \%$ ambos os períodos.

Com relação à segurança, $44 \%$ dos usuários não se sentem seguros enquanto 
realizam atividades no Parque, 35,5\% sentem-se seguros e 20,5\% sentem-se seguros com restrições, isto é, apenas em horários e/ ou locais restritos, ou apenas acompanhados.

No que se refere à qualidade da manutenção do Parque, 47,5\% dos usuários consideram-na regular, $36,5 \%$ boa, $10 \%$ ótima e $6 \%$ ruim.

O que mais atrai os entrevistados ao PCMB é o conjunto realização de atividades físicas e o contato com a natureza - $52 \%$, realização de atividades físicas - $18 \%$, lazer e contato com a natureza $-14,5 \%$, contato com a natureza $-11,5 \%$ e outros $-4 \%$.

A realização de atividades físicas também ficou em primeiro lugar na preferência dos usuários em diversos Parques: 22,24\% Parque Ingá-PR (TAKAHASHI eMARTINS, 1990), 54,73\% - Parque Oásis, Santa Maria-RS (SANTOS e TEIXEIRA, 1992), 50\% dos visitantes dos parques de São Paulo (SANTOS e COSTA, 2005) e 55\% - Parque Natural Municipal do Mendanha (TOMIAZZI et al., 2006).

É importante considerar que o PCMB é uma unidade de conservação na qual, legalmente, as atividades de educação e interpretação ambiental estão entre suas principais finalidades. $\mathrm{O}$ fato de apenas um dos entrevistados $(0,5 \%)$ fazer menção a esse tipo de atividade pode estar relacionado à baixa representatividade de ações nesse sentido.

\subsection{Importância atribuída às áreas verdes}

Quando perguntado aos frequentadores quanto à criação de mais parques e áreas verdes em Cuiabá, 89,5 \% dos entrevistados foram favoráveis a esse tipo de investimento.

A principal justificativa $(71,9 \%)$ foi o conjunto de benefícios gerados à população: "melhoria da qualidade de vida do cidadão, melhoria da qualidade ambiental da cidade, oferecem maior opção de lazer e melhoram o aspecto visual da cidade". Em segundo lugar ficou a alternativa "oferecem maior opção de lazer à população", com 28,1\%.

Os 10,5\% restantes disseram não serem favoráveis à criação de mais áreas verdes por considerarem prioridade maiores investimentos nas áreas verdes já existentes.

$$
\text { No Bosque do Alemão }
$$
(HILDEBRAND et al., 2002), 100\% dos entrevistados foram favoráveis a esse tipo de investimento.

\subsection{Disposição a pagar}

Os resultados da pesquisa mostram que $27,5 \%$ dos entrevistados estariam dispostos a pagar um valor de entrada para a manutenção do Parque da Cidade Mãe Bonifácia, sendo que a classe de valor que obteve a maior frequência foi a de $\mathrm{R} \$ 0,50 \mathrm{a}$ $\mathrm{R} \$ 1,00$, com $82,1 \%$ da preferência dos entrevistados dispostos a pagar.

Assim, a DAP média encontrada para o público disposto a pagar foi de $\mathrm{R} \$ 1,10$ por pessoa. Considerando o total de entrevistados (dispostos e não dispostos a pagar), essa média passa a ser de $R \$ 0,31$ por pessoa.

Expandindo o valor médio da DAP para a estimativa mensal de visitantes (20.000), obteve-se um valor agregado de $21.964,23 /$ mês e um valor anual de $\mathrm{R} \$ 263.571,43$. Observa-se que o valor agregado obtido representa $52,33 \%$ do orçamento anual disponibilizado para o parque pelo Governo Estadual, que é de $\mathrm{R} \$ 503.576,35$.

Em diversos estudos de valoração contingente de parques e áreas verdes urbanas, que utilizaram a DAP, as percentagens de visitantes dispostos a pagar foram superiores ao encontrado nesse estudo.

No Brasil, entre os frequentadores do Bosque do Alemão, 62,1\% estavam dispostos a pagar um valor de entrada, gerando um valor agregado de $\mathrm{R} \$ 2$ 29.040,00/ano; no Parque Metropolitano do Pituaçu-BA, o número de visitantes dispostos a pagar foi de $63,4 \%$ (SOUSA e MOTA, 2006), estimando-se um valor agregado de $\mathrm{R} \$ 2,28$ milhões/ano.

Ovalor agregado obtido para o Hartfield Park em Perth-Austrália (PEPPER et al., 2005) foi de \$A 3.3 milhões/ano, sendo que a disposição a pagar dos moradores foi de $77 \%$.

Na cidade de Guangzhou-China, $96,6 \%$ dos moradores foram favoráveis a pagar um valor de entrada para as áreas verdes urbanas (CHEN, 2005), percentagem notavelmente maior que em outras cidades. Observa-se que já existe a cobrança de taxas para entrada em algumas áreas verdes dessa cidade. O valor médio da DAP encontrada foi superior ao da taxa de entrada atual e o valor agregado atingiu RMB\$ 547 milhões/ 
ano, superando em seis vezes o valor que a cidade de Guangzhou investe em áreas verdes urbanas atualmente.

\subsubsection{Análise da DAP em relação às variáveis socioeconômicas}

Considerando a DAP segundo a renda familiar do PCMB (Figura 2), percebe-se que os visitantes que têm maior disposição a pa- gar (39,3\%) pertencem à faixa de renda entre três a cinco salários mínimos, seguidos pela faixa de renda de até um salário mínimo $(33,3 \%)$ e de até dez salários mínimos (31\%). Entre 1 e 3 salários mínimos o percentual de dispostos a pagar atinge $23,1 \%$ e entre 7 e 10 salários mínimos $22,2 \%$. A menor disposição a pagar encontrada foi na faixa de renda familiar entre cinco e sete salários mínimos com $12,9 \%$.

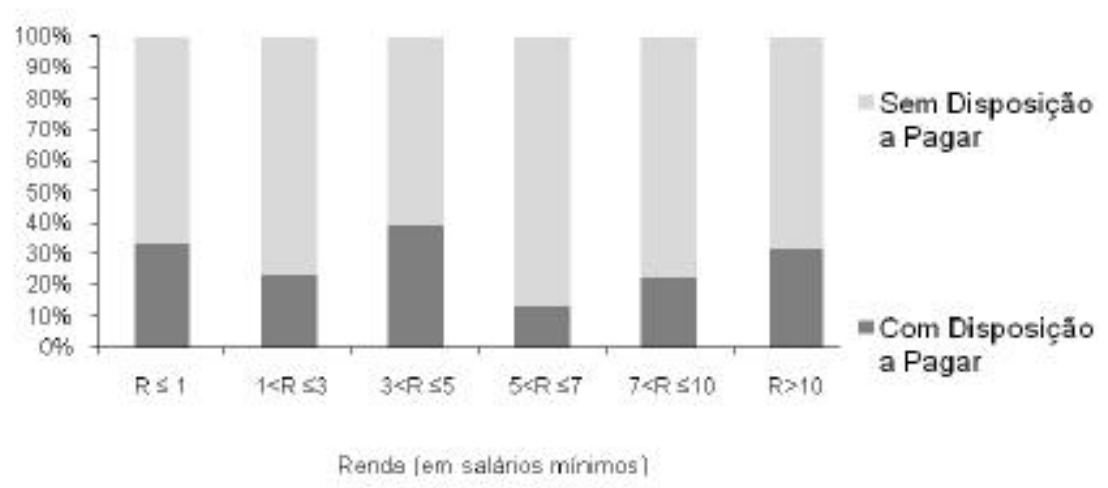

Figura 2 - Percentual dos visitantes dispostos a pagar conforme as categorias de renda familiar.

Observa-se que os visitantes com maior disposição a pagar possuem $1^{\circ}$ grau completo $(62,5 \%)$, seguidos pelos que possuem segundo grau incompleto $(60,0 \%)$ e dos que possuem ensino superior incompleto $(56,5 \%)$. Entre os que têm o $1^{\mathfrak{o}}$ grau incom- pleto o percentual de dispostos a pagar é de $28,6 \%$, e entre os que possuem curso superior completo, $28,3 \%$. A menor disposição a pagar foi encontrada entre os que possuem segundo grau completo, com apenas 1,9\%, como mostra a Figura 3.

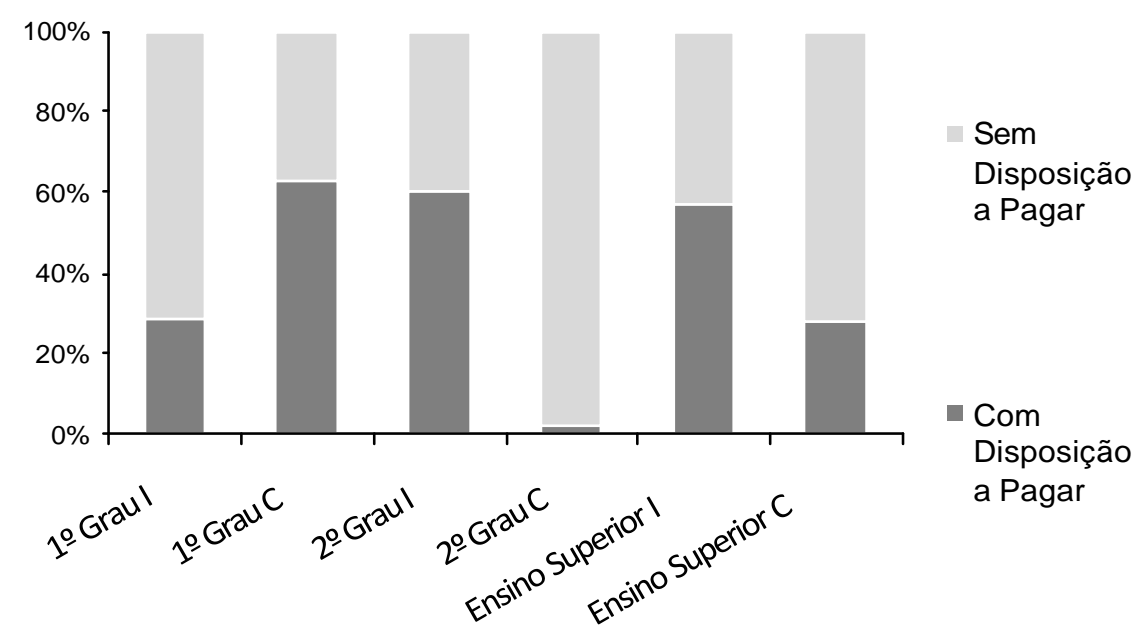

Figura 3 - Percentual dos visitantes dispostos a pagar conforme as categorias de nível de escolaridade. 
Hildebrand et al. (2004) e Sousa e Mota (2006) apontaram que a disponibilidade econômica e o nível de escolaridade foram superiores entre os entrevistados dispostos a pagar. Nos estudos realizados por Pepper et al. (2005) e Chen (2005), a disposição a pagar foi significativamente associada à renda dos moradores, porém, quanto à escolaridade, a DAP foi maior entre os entrevistados de nível médio.
É interessante observar a relação entre a DAP e a origem dos visitantes do PCMB (Figura 4), percebendo-se uma maior disposição a pagar entre os visitantes de outras cidades $(40 \%)$ do que entre os que residem em Cuiabá $(27,2 \%)$. Como se trata do pagamento de um valor para a entrada, esse resultado pode estar relacionado com o fato de os moradores da cidade visitarem o parque com maior frequência.

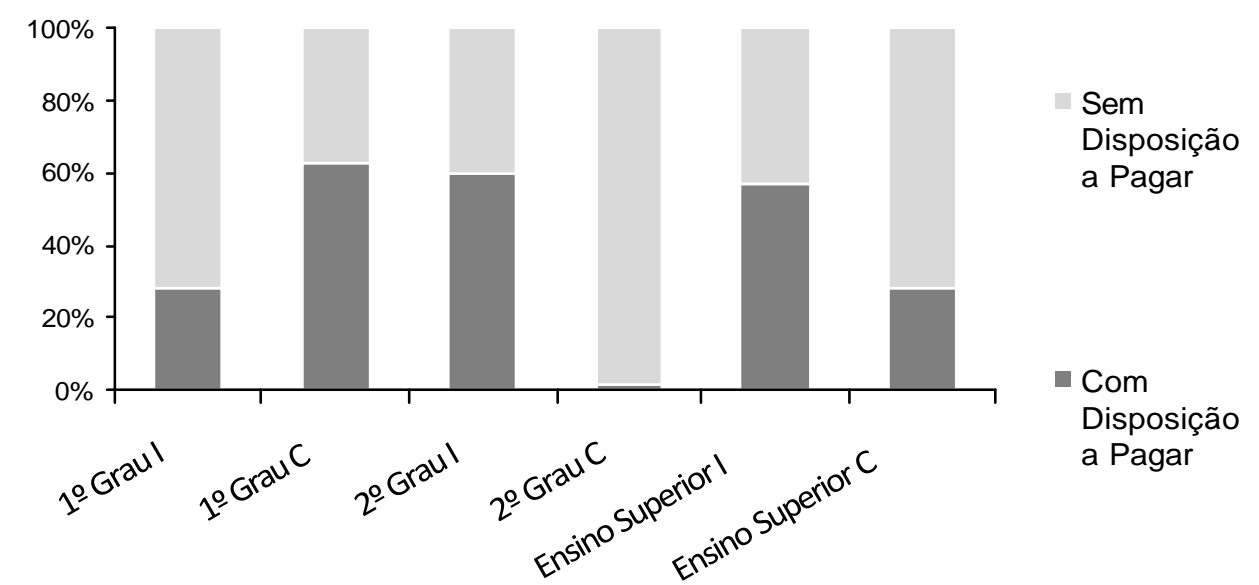

Figura 4 - Percentual dos visitantes dispostos a pagar, conforme a frequência.

Quanto à frequência, o grupo com maior disposição a pagar é dos que visitavam o Parque pela primeira vez, com $40 \%$, seguido pelos que frequentam até duas ve- zes na semana (31\%), mais de três vezes na semana, com $27,3 \%$, e dos que frequentam ocasionalmente, com 23\% (Figura 5).

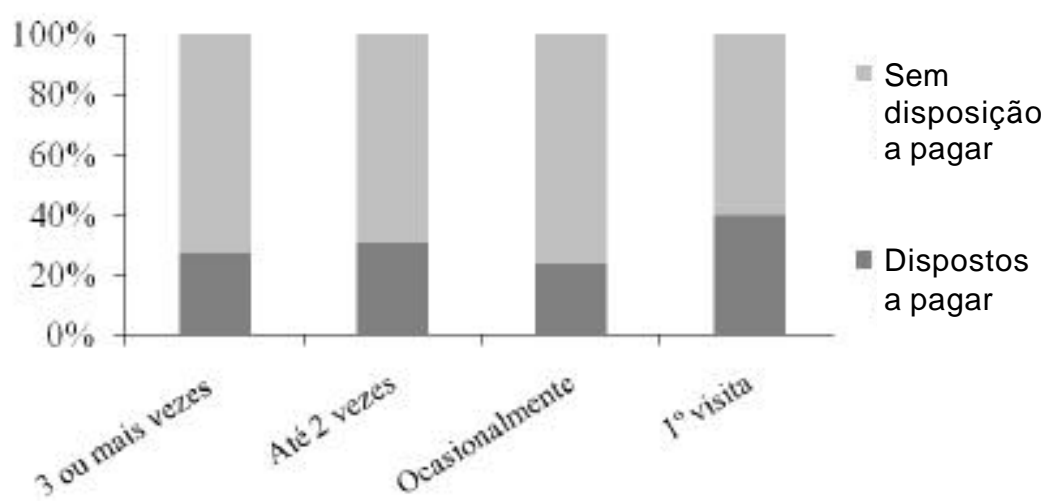

Figura 5 - Percentual dos visitantes dispostos a pagar conforme a frequência.

Analisando o valor de entrada atribuído em função da frequência e das atividades preferidas dos visitantes com disposição a pagar, observou-se que o maior valor médio obtido foi para o conjunto de atividades: atividade física e apreciação da natureza (Tabela 4). 
Tabela 4 - Valor médio de entrada atribuído em função da frequência e das atividades preferidas dos visitantes dispostos a pagar.

\begin{tabular}{lcc}
\hline \multicolumn{1}{c}{ Atividade Preferida } & $\%$ & $\mathbf{R} \$$ \\
Atividade Física + Apreciar a natureza & $55,4 \%$ & 8,68 \\
Atividade Física & $17,9 \%$ & 2,72 \\
Lazer & $10,7 \%$ & 1,72 \\
Apreciar a natureza & $10,6 \%$ & 1,72 \\
Lazer + Apreciar a natureza & $3,6 \%$ & 1,88 \\
Atividade física + lazer & $1,8 \%$ & 0,05 \\
Eventos & $0 \%$ & 0,00 \\
\hline
\end{tabular}

Observa-se que $72,5 \%$ dos entrevistados não se dispuseram a contribuir com nenhum valor para manutenção e preservação do PCMB. Diversos motivos explicam o não pagamento da contribuição.

A Tabela 5 faz uma descrição das justificativas para os lances nulos, verificando- se que as respostas que indicam o viés de protesto: a) a manutenção de parques e áreas verdes é função do governo e b) os impostos pagos deveriam cobrir esse tipo de despesa, destacam-se como principal fator explicativo da DAP nula, agrupando $78,3 \%$ das respostas.

Tabela 5 - Justificativas para a "disposição a não pagar" um valor de entrada para a manutenção e conservação do PCMB.

\section{Motivo da "disposição a não pagar"}

$\%$

A manutenção de parques e áreas verdes é função do governo

$48,3 \%$

Os impostos pagos deveriam cobrir esse tipo de despesa

$30,0 \%$

Não acreditam que com a cobrança de entrada o Parque será mais bem conservado

A cobrança restringiria a visitação

$10,3 \%$

Aproximadamente $65,9 \%$ dos entrevistados sugeriram como solução para as dificuldades financeiras na manutenção do PCMB a correta aplicação do orçamento público, enquanto $15,8 \%$ apontaram a realização de parcerias com empresas.

\subsection{Valorização imobiliária como referên- cia para valoração de áreas verdes}

Partindo da necessidade de valorar economicamente parques eáreas verdes sem que fosse necessário questionar quanto ao pagamento pelo acesso a essas áreas, diversos estudos utilizaram o método de preços hedônicos com o objetivo de obter um valor para essas áreas a partir da análise do preço dos imóveis em suas proximidades.
No estudo realizado por Dunse et al. (2007), foi analisado o efeito da proximidade de parques urbanos e espaços abertos nos valores de residências em Aberdeen, Escócia. Os resultados mostraram que imóveis a até $450 \mathrm{~m}$ de distância de parques tiveram um acréscimo em seus valores de até 19,97\%, variando conforme o tipo de residência e do tamanho do parque.

Alkay (2005), Jim e Chen (2006) e Kong et al. (2007), também utilizando o método de preços hedônicos, demonstraram que a proximidade de parques de uso público ou áreas verdes aumenta significativamente o preço dos imóveis residenciais.

Martins (2005) constatou um aumento de edificações e valorização dos imóveis no entorno do PCMB desde a sua criação, sendo 
que $28 \%$ dos moradores de edifícios em seu entorno afirmaram que a proximidade com o parque foi o principal motivo para a aquisição do imóvel.

Considerando a procura e a valorização dos imóveis no entorno do PCMB, a utilização da metodologia acima citada possivelmente captará melhor o valor econômico desse ativo ambiental do que a valoração contingente.

\section{Conclusões}

As variáveis socioeconômicas indicaram um padrão entre médio e alto para os usuários do PCMB sendo que, para a maioria dos entrevistados, o maior atrativo da área é o conjunto realização de atividades físicas e contato com a natureza.

Quanto ao fato de a maior parte dos frequentadores morarem nas proximidades do parque, é possível fazer duas observações: a primeira é que a maior parte dos visitantes prefere não percorrer longas distâncias, optando por frequentar o parque mais próximo a sua residência; a segunda é que os visitantes que são moradores de bairros distantes provavelmente não dispõem de um parque na região de sua residência, o que deve ser considerado no planejamento e gestão dessas áreas.

Constatou-se que apenas $27,5 \%$ dos usuários do parque estariam dispostos a pagar um valor de entrada para a conservação e manutenção do PCMB e grande parte dos entrevistados não dispostos a pagar deixaram evidente que a manutenção da área é uma atribuição do governo.

Porém, a população se mostrou favorável a um maior investimento do governo em parques e áreas verdes na cidade. A principal justificativa $(71,9 \%)$ foi o conjunto de benefícios gerados à população: "melhoria da qualidade de vida do cidadão, melhoria da qualidade ambiental da cidade, oferecem maior opção de lazer e melhoram o aspecto visual da cidade". Em segundo lugar, ficou a alternativa "oferecem maior opção de lazer à população", $\operatorname{com} 28,1 \%$.

\section{Referências}

ALKAY, E. Measurement of urban green areas' economic values: The Case of Istanbul. In: EUROPEAN NETWORK FO HOUSING RESEARCH INTERNATIONAL HOUSING CONFEREFENCE. Reykjavik, Iceland, 2005. 10 p. Disponível em: <http://www.borg.hi.is / enhr2005iceland/ppr/alkay.pdf>. Acesso em: 3 fev. 2008.

BENAKOUCHE E., R.; CRUZ, R. S. Avaliação monetária do meio ambiente. São Paulo: Makron Books, 1994. 198 p.

CAVALHEIRO, F.; DEL PICCHIA, P.C.D. Áreas Verdes: conceitos, objetivos e diretrizes para o planejamento. In: CONGRESSO BRASILEIROSOBRE ARBORIZAÇÃO URBANA. Anais... Vitória: PMV, 1992. p. 29-38.

CHEN, W.Y. Valuing Ecosystem Services of Recreational Opportunities and Amenities Generated by Green Spaces in Guangzhou. In: CHINESE CITIES IN TRANSITION: THE NEXT GENERATION OF URBAN RESEARCH, Part 4. July 7-9 ${ }^{\text {th }}, 2005$. Disponível em: <http://mumford.albany.edu/chinanet/ shanghai2005/chenyan_en.doc $>$. Acesso em: 30 jan. 2008.

COCHRAN, W. G. Sampling Techniques. New York: John Wiley e Sons, 1977. 428p.

CUIABÁ. Lei complementar n. 004 de 24 de dezembro de 1992.

CUNHA e MENEZES P. Raising the priority of urban areas in protected area systems in Brazil and beyond. In: TRZYNA, T. The Urban Imperative: Urban Outreach Strategies for Protect Areas Agencies. Sacramento: California Institute of Public Affairs. 2005. Disponível em: <http://www.interenvironment.org/pa/ menezes.htm>. Acesso em: 4 jun. 2006.

DUNSE, N.; WHITE, M.; DEHRING, C. Urban parks, open spaces and residential property values. RICS, v. 7, n. 8, 2007. 8 p. Disponível em: <http://www.rics.org/NR/ rdonlyres/BA2D15CE-FD78-4D49-A55F-AFF4300D1B/ 0/3959_urban_parksLowresversionforweb.pdf>.Acesso em: 3 fev. 2008.

HILDEBRAND, E.; GRAÇA, L.; HOEFLICH, V. "Valoração Contingente" na avaliação econômica de áreas verdes urbanas. Revista Floresta (1), p. 121-132, 2002.

JIM, C.Y.; CHEN W.Y. Impacts of urban environmental elements on residential housing prices in Guangzhou (China). Landscape and Urban Planning, v. 78, p. 422-434, 2006. Disponível em: <doi:10.1016/j.landurbplan. 2005.12.003>. Acesso em: 2 fev. 2008.

KONG, F.; YINB, H.;NAKAGOSHIA, N. Using GIS and landscape metrics in the hedonic price modeling of the amenity value of urban green space: A case study in Jinan City, China Landscape and Urban Planning, v. 79, p. 240-252, 2007. Disponível em: <doi:10.1016/ j.landurbplan.2006.02.013>. Acesso em: 5 fev. 2008.

MALTA, R. R. Valoração econômica dos serviços recreativos e ecoturísticos em uma unidade de conservação - o caso do Parque Nacional da Tijuca (RJ). 2008. Dissertação (Mestrado em Geografia) - Universidade do rio de Janeiro, Rio de Janeiro-RJ. 
MARTINS, E.C. Natureza na cidade, a verticalização no entorno do Parque Mãe Bonifácia em Cuiabá-MT.2005. 117f. Dissertação (Mestrado em Geografia) - Universidade Federal de Mato Grosso, Cuiabá-MT.

MATO GROSSO. Decreto de n. 1.470 de 9 de junho de 2000.

MOTA J. A. O valor da natureza: economia e política dos recursos ambientais. Rio de Janeiro: Garamond Universitária, 2001. 200 p.

ORTIZ, R. A.; MOTTA, R. S.; FERRAZ, C. Estimando o valor ambiental do Parque Nacional do Iguaçu: uma aplicação do método de custo viagem. Texto para Discussão. Rio de Janeiro: IPEA, 2001. 31 p. Disponível em: <http://www.ipea.gov.br/pub/td/td_2001/ td0777.pdf.>. Acesso em: 13 fev. 2006.

PEPPER, C.; MCCANN, L.; BURTON, M Valuation study of urban bushland at artfield Park, Forrestfield, Western Austrália. Ecological Management e Restoration, v. 6, n. 3, p. 190-196, 2005. Disponível em: <http:// www.blackwell-synergy.com/doi/pdf/10.1111/ j.1442-8903. 2005. 00236.x>. Acesso em: 3 fev. 2008.

PERON, D. O Parque Florestal de Sinop (MT) e sua importância para a educação ambiental. 2003. Dissertação (Mestrado em Educação) - Universidade Federal de Mato Grosso, Cuiabá-MT.

SANTOS, G.E.O; COSTA, B.V. Perfil dos visitantes dos parques da cidade de São Paulo. Caderno Virtual de Turismo, v. 5, p. 39-45, 2005.

SANTOS, N. R. Z.; TEIXEIRA, I. F. Caracterização do perfil dos visitantes do Parque Oásis, Santa Maria, RS. In: CONGRESSO BRASILEIRO DE ARBORIZAÇÃO URBANA. Anais... Curitiba: UFPR, 1992. p. 409-422.

SOUSA, J. A.; MOTA, R.S. Valoração econômica de áreas de recreação: o caso do Parque Metropolitano de
Pituaçu, Salvador, BA. Revista de Economia, v. 32, n. 1, p. 37-55, 2006.

TAKAHASHI, L. Y.; MARTINS, S. S. O perfil dos visitantes de um Parque Municipal situado no perímetro urbano. IN: ENCONTRO NACIONAL SOBRE ARBORIZAÇÃO URBANA. Anais... Curitiba: UFPR/FUPEF, 1990. p. 197-210.

TOMIAZZI, A.B. VILLARINHO, F.M., MACEDO, R.L.G, VENTURIN, N. Perfil dos visitantes do Parque Natural Municipal do Mendanha, município do rio de janeiro RJ. Cerne, v. 12, p. 406-411, 2006.

OUZA, Marcelo L. Algumas notas sobre a importância do espaço para o desenvolvimento social. Revista Território, v. 3, p. 14-35, 1997.

JACOBY, Russell. Os últimos intelectuais: a cultura americana na era da academia. Trad. Magda Lopes. São Paulo: Trajetória/Edusp, 1990.

SANTOS, Milton. A natureza do espaço: técnica e tempo, razão e emoção. São Paulo: Hucitec, 1996.

A redefinição do lugar. In: ENCONTRO NACIO-NAL DA ASSOCIAÇÃO NACIONAL DE PÓSGRADUAÇÃO EM GEOGRAFIA, 1995, Aracaju. Anais... Recife: Associação Nacional de Pós-Graduação em Geografia, 1996, p. 45-67.

. O espaço do cidadão. São Paulo: Nobel, 1987.

SOJA, Edward. Geografias pós-modernas: a reafirmação do espaço na teoria social crítica. Rio de Janeiro: Jorge Zahar, 1993.

SOUZA, Marcelo L. Algumas notas sobre a importância do espaço para o desenvolvimento social. Revista Território, v. 3, p. 14-35, 1997.

WIENER, Norbert. Cibernética e sociedade: o uso humano de seres humanos. 9. ed. São Paulo: Cultrix, 1993. 